\title{
DIGITAL ELEVATION MODEL VALIDATION WITH NO GROUND CONTROL: APPLICATION TO THE TOPODATA DEM IN BRAZIL
}

Validação de modelos digitais de elevação sem dados de referência: Aplicação ao MDT Topodata no Brasil

\author{
LAURENT POLIDORI ${ }^{1,2}$ \\ MHAMAD EL HAGE ${ }^{3}$ \\ MÁRCIO DE MORISSON VALERIANO ${ }^{4}$
}

${ }^{1}$ CNAM / L2G, 1 boulevard Pythagore, 72000 Le Mans, France

${ }^{2}$ UNESP, Departamento de Cartografia

Rua Roberto Simonsen, 305, 19060-900, Presidente Pudente, S.P., Brazil

${ }^{3}$ CNRS, P.O. Box : 11-8281, Riad El-Solh 1107 2260, Beirut, Lebanon

${ }^{4}$ INPE / DS, av. dos Astronautas, 1758, São José dos Campos, S.P., Brazil

laurent.polidori@esgt.cnam.fr; mhamad.elhage@yahoo.com;

valerian@dsr.inpe.br

\begin{abstract}
Digital Elevation Model (DEM) validation is often carried out by comparing the data with a set of ground control points. However, the quality of a DEM can also be considered in terms of shape realism. Beyond visual analysis, it can be verified that physical and statistical properties of the terrestrial relief are fulfilled. This approach is applied to an extract of Topodata, a DEM obtained by resampling the SRTM DEM over the Brazilian territory with a geostatistical approach. Several statistical indicators are computed, and they show that the quality of Topodata in terms of shape rendering is improved with regards to SRTM.
\end{abstract}

Keywords: Digital Elevation Model; Topodata; SRTM DEM.

\section{RESUMO}

A validação de modelos digitais de elevação (MDE) consiste geralmente na comparação dos dados com um conjunto de pontos de controle. Porém, a qualidade de um MDE também pode ser considerada em termos de realismo das formas. Além 
da análise visual, pode ser verificado que propriedades físicas e estatíticas do relevo terrestre são cumpridas. Essa abordagem é aplicada a um extrato do Topodata, um MDE obtido pela reamostragem do MDE SRTM sobre o território brasileiro com uma abordagem geostatística. Vários indicadores estatísticos são calculados. Mostram que a qualidade de Topodata em termos de descrição das formas é melhorada com relação ao SRTM.

Palavras-Chave: Modelos Digitais de Elevação; Topodata; SRTM DEM.

\section{INTRODUCTION}

Digital elevation models (DEMs) are commonly used to describe the 3D geometry of the Earth surface for a variety of applications such as landscape synthesis, hydrologic modelling or geological hazard assessment. Satellite images have been increasingly used in the past two decades to provide DEMs, mainly through photogrammetry or radar interferometry (TOUTIN and GRAY, 2000). The quality of these data has been regularly studied, both to improve the mapping methods and to evaluate their applicative potentialities. Most experiments carried out for the validation of a single DEM or a DEM production method consist in comparing the obtained data with a reference data set, generally a set of ground control points. This comparison may be based on statistical accuracy indicators such as mean difference, standard deviation or RMSE (root mean square error), and when the GCPs are numerous and well distributed the error can be interpolated and mapped. This validation approach is very relevant to evaluate the positional accuracy of the DEM. However, many applications require a good rendering of terrain shapes and a high positional accuracy does not guarantee that his requirement is fulfilled, since accurate slopes are required rather than accurate elevations. In this article, we propose several quality criteria to validate DEMs in terms of shape rendering. The characteristic of these criteria is that they are difficult to implement with ground control, and they can rather be based on reasonable hypotheses concerning geomorphological rules that all topographic surfaces are supposed to fulfil.

Among the attempts to provide a world wide elevation data base, the most noticeable one is the Shuttle Radar Topography Mission (SRTM) that resulted in a homogeneous DEM with a 3 arc seconds (around $90 \mathrm{~m}$ ) grid mesh (FARR and KOBRICK 2001).

In Brazil, the Instituto Nacional de Pesquisas Espaciais has proposed another DEM called Topodata, obtained by resampling the SRTM DEM to create a 1 arc second $(\sim 30 \mathrm{~m})$ grid with a geostatistical interpolation approach (VALERIANO and ROSSETTI, 2012). Since the selection of geostatistical coefficients for this interpolation considered the likelihood of DEM features relative to natural terrain shape, it was relevant to evaluate the improvement achieved with regards to the input SRTM in terms of shape realism. 
Our method for DEM validation without ground control is based on a set of realism requirements (POLIDORI, 1995; OKSANEN, 2003; EL HAGE, 2012). This article presents a study in which these requirements are discussed and tested on a Topodata DEM in Eastern Brazil.

In section 2 the study area and the data are described. Geomorphological quality criteria are proposed for DEM validation in section 3. The results are presented in section 4 and discussed in section 5.

\section{STUDY AREA AND DATA DESCRIPTION}

\subsection{Study Area}

The study area covers about $82000 \mathrm{~km}^{2}$ in Eastern Brazil, including the main part of the Brazilian states of Rio de Janeiro and Espirito Santo and the Eastern part of the Minas Gerais state. It is a coastal watershed, chosen for the variety of reliefs, with a coastal plain and a hilly strip dominated by a mountainous chain called Serra do Espinhaço. Elevations range from 0 to $2600 \mathrm{~m}$ asl. This mountainous system has a SSW-NNE general orientation parallel to the coast and a dense hydrographic network mainly streaming ESE. It is characterized by a complex geomorphology, which is the result of both tectonic and hydrologic processes (SAADI 2013).

Figure 1 - Location of the study area and its topography (SRTM DEM).

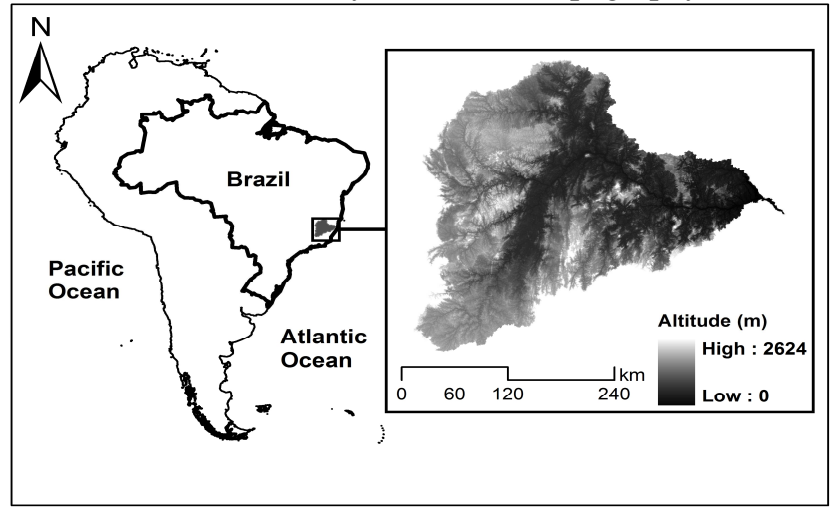

\subsection{SRTM Elevation Model}

A digital elevation model from the SRTM version 1 data base was extracted over the study area. The SRTM covers the main part of continental surfaces between latitudes $60^{\circ} \mathrm{N}$ and $56^{\circ} \mathrm{S}$, due to the inclination of the orbital plane. This DEM was obtained by dual antenna SAR interferometry and sampled with a 1" (one arc sec) mesh. A world wide data base with a subsampled 3" mesh is available for free download. Over the US territory only, a 1" DEM is also available. Since this DEM is widely used in many areas of the world and for many applications, its quality has 
often been evaluated. Its validation has mainly consisted in the evaluation of its position accuracy based on theoretical considerations concerning SAR interferometry capabilities and on ground control points. According to Rabus et al. (2003), the SRTM DEM has an absolute vertical accuracy of $16 \mathrm{~m}$ and a horizontal accuracy of $20 \mathrm{~m}$. In a post-launching evaluation for South American data, Rodriguez et al. (2006) report the same features to be around $6.2 \mathrm{~m}$ and $9.0 \mathrm{~m}$, respectively. In forested areas, this error is increased by the presence of trees since the C-band beam used by SRTM penetrates only partially into the canopy (KELLNDORFER et al., 2004), according to a complex combination of density, arrangement and dielectric properties of canopy elements and average tree height (LE TOAN et al., 1992). This effect represents a striking limitation for its use in low relief and dense and high canopy conditions, the prevailing condition in Amazonia biome (VALERIANO et al., 2006). Other studies have aimed at determining the actual resolution of SRTM using spectral analysis (SMITH and SANDWELL 2003).

The effect of resolution on accuracy and on the performance of topographic derivations, are known (LI, 1992). Elevation data in coarse resolution are likely to produce decreased results in topographic derivations due to the larger horizontal distances applied in their calculations. The geometric expression of the pixel structure is also enhanced at coarse resolution, allowing the occurrence of unrealistic features in the DEM. These effects motivated the refinement of SRTM data from 3" to 1" by different authors using diverse techniques (KEERATIKASIKORN and TRISIRISATAYAWONG, 2008; EHSANI et al., 2010; METZ et al., 2010). These refinement techniques do not represent a real improvement on DEM resolution, but are considered as a recommendable care to partially overcome resolution effects upon the lack of high resolution data.

\subsection{Topodata Elevation Model}

In Brazil the SRTM database has been resampled in order to generate a 1" mesh DEM over the whole national territory in the scope of a geomorphometric database called Topodata. The resampling process is based on kriging interpolation, which requires a set of geostatistical coefficients describing data spatial variability. Since these coefficients are determined through a geostatistical analysis of a data subset, a key task for Topodata development was the selection of a single coefficient set among a large number of analyses for a unified interpolation (VALERIANO and ROSSETTI, 2012). This selection was conducted with assistance of visual analysis of shaded relief presentations, and targeted the preservation of the highest level of detail in the expression of natural landforms.

\section{GEOMORPHOLOGICAL CRITERIA FOR DEM VALIDATION}

The research on SRTM quality mostly relies on the analysis of RMSE with regards to a known reference data (MILIARESIS \& PARASCHOU, 2005; RODRIGUEZ et al., 2006; WEYDAHL et al., 2007; BHANG et al., 2007). Miceli

Bol. Ciênc. Geod., sec. Artigos, Curitiba, v. 20, nº 2, p.467-479, abr-jun, 2014. 
et al. (2011) used field validation points for a similar comparative study with mostly GDEM (Global Digital Elevation Map), SRTM-1, SRTM-4 and Topodata, and included slope together with elevation in RMSE analysis.

Since the Topodata DEM is based on the SRTM data it is expected to have a similar quality in terms on positional accuracy. The relationship between a refined DEM (Topodata) and its original data (SRTM) had already been explored in an alternative evaluation method based on cross-validation, proposed by Wise (2001). This research, which involved slope, aspect and curvature besides elevation, used the (USA) SRTM-1" as reference for assessing interpolation results of SRTM-3", and its derivatives. Despite the broadness and effectiveness of this approach, this method of cross-validation requires the access to the 1" SRTM data, what is possible only for the United States. In the present research, a statistical analysis of the difference between both DEMs was performed preliminary, in terms of mean difference, standard deviation and RMSE in order to verify that the quality of SRTM is terms of absolute position is statistically preserved in the Topodata DEM.

Evaluating the quality of a DEM in terms of shape rendering is less straightforward. The comparison of a terrain shape as modelled in the evaluated DEM with a reference is limited by the fact that height derivatives (slope, aspect, curvature) and therefore shapes are not stable with regards to scale, while elevation is stable (EL HAGE et al. 2010). For this reason, it is much more convenient to evaluate the morphological realism of a DEM by analysing its compliance to a number of general rules that the terrestrial relief is supposed to fulfil. We can distinguish two requirement levels, called strong and weak requirements.

Strong requirements are defined by physical rules and a terrain that does not fulfil them is impossible. According to this approach, we made one experiment consisting in verifying the fulfilment of one simple rule: water always streams downward. In practice, this means that the detection of local sinks along the hydrographic network and even elsewhere in the watersheds can be used to locate and quantify DEM errors. The hydrographic network was automatically extracted from the DEM. The sinks were detected, their occurrence was calculated in percentage and their mean depth was calculated to evaluate the compliance of this physical rule. The results were compared to those obtained with SRTM data.

Weak requirements are defined by statistical rules and a terrain that does not fulfil them is improbable, although not impossible. According to this approach, we made the following experiments:

We verified that the DEM has a fractal behaviour, which is often the case of terrains modelled by hydric erosion (RODRIGUEZ-ITURBE \& RINALDO 1997), i.e. a small area has the same statistical properties as a reduced copy of a larger one in the same region. This can be illustrated by Horton's law which states that if the river streams are classified by Strahler orders, the total number of streams of a given order decreases in a geometric progression when the order number increases. The hydrographic network was classified with Strahler orders. For each order N, the logarithm of the total number of streams of order $\mathrm{N}$ was plotted against $\mathrm{N}$ and a 
linear regression line was computed in order to evaluate the linearity of this relationship. This indicator cannot be compared with the results obtained with SRTM, since a given drainage segment has no reason for having the same order in both DEMs.

We analyzed the statistical distribution of elevation derivatives, i.e. slope and aspect. The histograms of these derivatives were computed in order to reveal potential unlikely effects produced by the elevation computing and resampling processes. They were also computed after the DEM had been subsampled with increasing ratio of $3,6,12,24$ in order to analyse the effect of scale. At each scale, the histograms of slopes and aspects are compared with the same histograms obtained from SRTM data, in order to detect the potential impact of the resampling procedure on the local shapes.

The quality criteria described above were used to evaluate the absolute position coherence with regards to the input SRTM DEM, and to detect possible artefacts affecting elevation derivatives and therefore terrain shape rendering in order to contribute to the quality assessment of the Topodata DEM in view of its geomorphologic application.

Visual analysis and thematic experiments are not considered in this paper, but they can also contribute to geomorphological quality assessment with no reference data (OKSANEN, 2003; VALERIANO and ROSSETTI, 2012).

\section{RESULTS}

The difference of elevation between SRTM and Topodata DEMs has been evaluated in terms of mean difference, standard deviation and RMSE. The results are given in table 1. The Topodata DEM generation did not create elevation bias, and it introduced a variability of elevation which is characterized by a RMSE of $17.8 \mathrm{~m}$. It was an expected result using kriging. This variability is necessary to compensate the fact that a $90 \mathrm{~m}$ mesh implicitly creates a smooth surface at $30 \mathrm{~m}$ scale. However, no further interpretation of these values can be made in terms of error without ground control. In other words, these values provide no information about the accuracy of the DEM.

Table 1 - Comparison between SRTM and Topodata DEMs.

\begin{tabular}{c|c}
\hline & $\begin{array}{c}\text { Difference of elevation between } \\
\text { SRTM and Topodata }(\mathrm{m})\end{array}$ \\
\hline Mean difference & 0.3 \\
\hline Standard deviation & 17.7 \\
\hline RMSE & 17.8 \\
\hline
\end{tabular}

In order to verify the compliance of the rule which states that water always streams downward, the sinks were detected and their depths were averaged. The results are presented in table 2 . In the Topodata DEM, a lower number of local 
sinks, less deep than the SRTM DEM were found, in spite of the elevation variability generated by the oversampling procedure. This implies that Topodata has a better compliance of this rule than SRTM, a previous expectation due to the chosen interpolation model (VALERIANO and ROSSETTI, 2012), which tends to compress positive and negative local outliers (peaks and sinks, respectively).

Table 2 - Percentage of sinks in SRTM and Topodata DEMs.

\begin{tabular}{c|c|c}
\hline & SRTM (\%) & Topodata (\%) \\
\hline Percentage of sinks & 1.8 & 0.72 \\
\hline
\end{tabular}

Table 3 - Statistical analysis of sink depths.

\begin{tabular}{c|c|c}
\hline & SRTM $(\mathrm{m})$ & Topodata $(\mathrm{m})$ \\
\hline Mean depth & 5.8 & 4.2 \\
\hline Standard deviation & 5.2 & 4.4 \\
\hline RMS & 7.8 & 6.1 \\
\hline
\end{tabular}

The fractal behaviour of the Topodata DEM was studied. Figure 2 represents the variation of the logarithm of the number of streams for each Strahler order as a function of this order. As expected according to Horton's law, a linear tendency with $\mathrm{R}^{2}=0,9836$ is observed over 12 orders (Figure $2 \mathrm{a}$ ), which means that the relief described by the DEM is nearly fractal. However, it appears that excluding the values obtained for orders 1 and 2, and plotting the results for orders 3 to 12 only, increases the linearity with $\mathrm{R}^{2}=0,9965$. This suggests that the Topodata resampling process slightly increases the number of short streams with regards to a fractal hypothesis, what could be confirmed in the evaluation of stream extraction among several DEMs (Topodata and SRTM included) by Fernández (2011). This interpretation could also be related with the increased elevation variability observed earlier in table 1.

Figure 2 - Fractal behaviour of the hydrographic network as illustrated by the variation of the logarithm of the number of streams for each Strahler order as a function of this order, for orders 1 to 12 (fig. 2a) and 3 to 12 (fig. 2b).

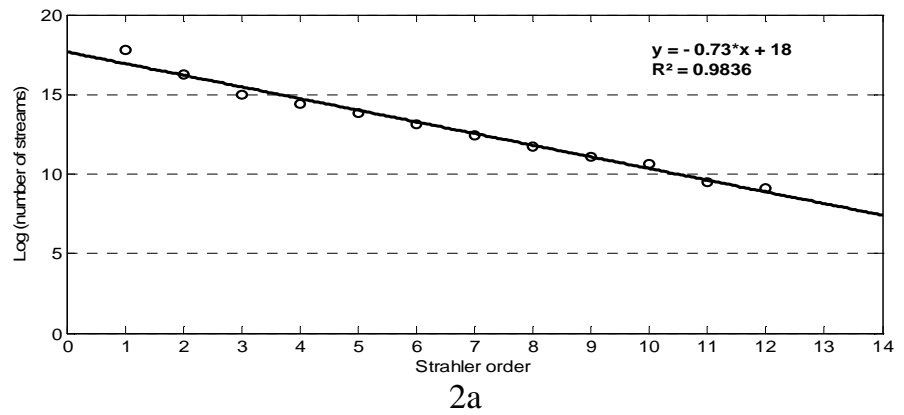

Bol. Ciênc. Geod., sec. Artigos, Curitiba, v. 20, nº 2, p.467-479, abr-jun, 2014. 


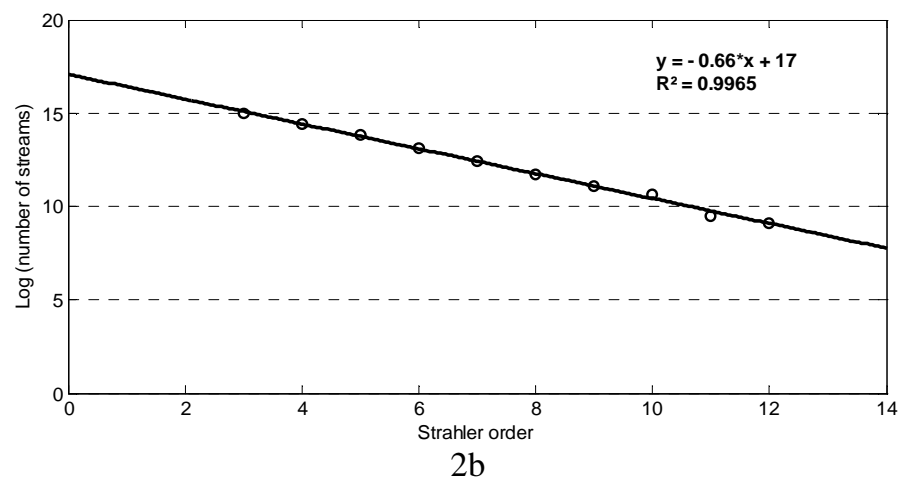

The slope histograms were computed in both SRTM and Topodata DEMs at different horizontal scales: $90 \mathrm{~m}, 180 \mathrm{~m}, 360 \mathrm{~m}, 720 \mathrm{~m}$ (Figure 3). We observed a perfect fit at scales available for both DEMs, which confirms the coherence of Topodata with regards to the input SRTM DEM for shapes larger than $90 \mathrm{~m}$. These histograms also show that slopes measured over shorter distances have a higher mean value and a higher standard deviation, as generally observed (EL HAGE 2012). This is another way to illustrate the fractal nature of terrain at the corresponding scales.

Figure3 - Slope histograms of SRTM and Topodata DEMs for different spatial mesh sizes (indicated on graph).

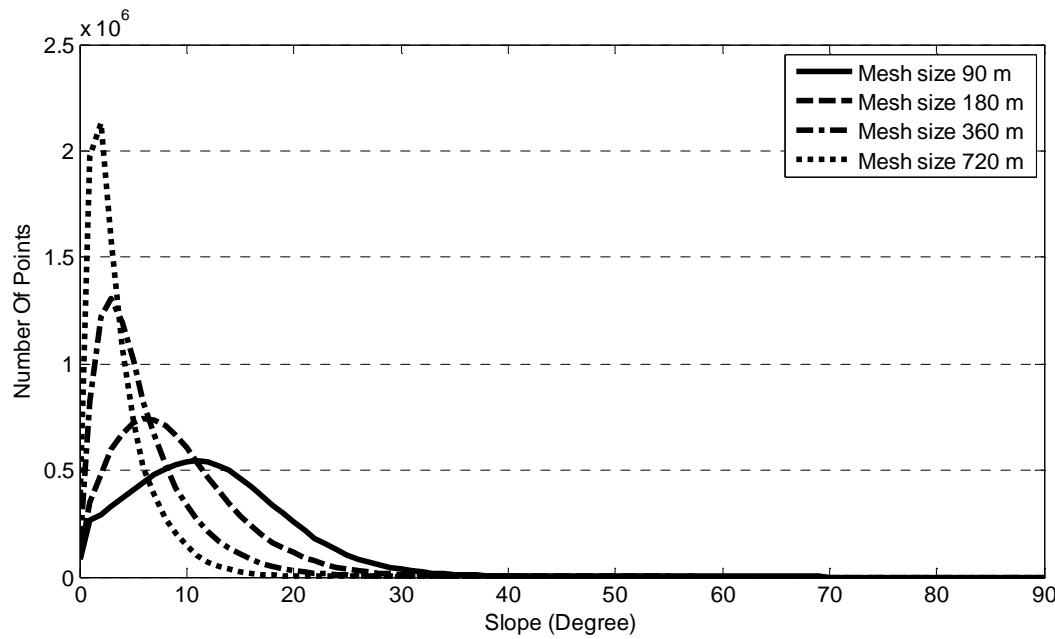

Bol. Ciênc. Geod., sec. Artigos, Curitiba, v. 20, nº 2, p.467-479, abr-jun, 2014. 
The aspect histogram was computed for SRTM and Topodata. The two histograms have the same overall shape, which reflects the general spatial organization of relief is this region. The main occurrence is the ESE direction as expected. The main difference between the two histograms is the presence of directional artefacts in the SRTM data. This is due to the square mesh structure which forces the local surface to be oriented with a multiple of $45^{\circ}$ with regards to North.

Four secondary peaks can be observed in each quadrant. They correspond to the diagonal orientations of small rectangular facets with sizes of $1 \times 3,1 \times 2,2 \times 1,3 \times 1$ respectively. Indeed, the arctangent values of the resulting azimuths are $18.5^{\circ}$, $26.5^{\circ}, 63.5^{\circ}$ and $71.5^{\circ}$ respectively, as illustrated in figure 4 .

The comparison of the two aspect histograms shows that the Topodata DEM sampling procedure respects the overall orientation of the topographic surface and does not produce noticeable artefacts. This difference between the two DEMs is illustrated in fig.5, where a detail of the hydrographical network extracted from both DEMs clearly shows that the Topodata DEM is not subject to important directional artifacts. The two networks are topologically consistent and they fit each other in terms of position, but the realism is improved in Topodata.

Fig. 4 - Aspect histograms of SRTM and Topodata DEMs (left) and angles of major occurrence corresponding to the peaks of the SRTM aspect histogram (right).
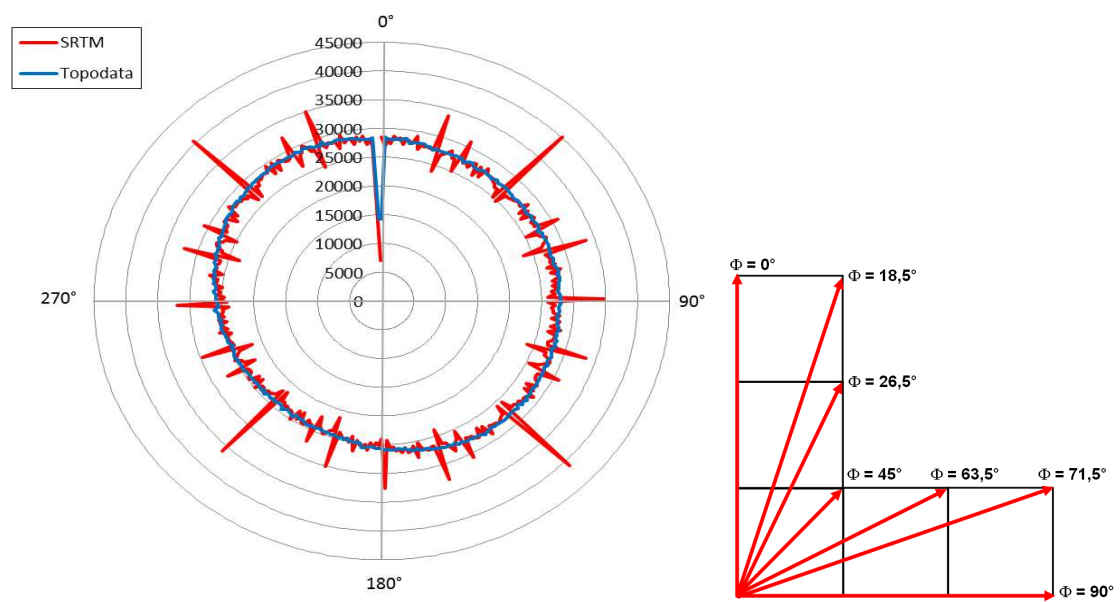
Fig. 5 - Detail of the hydrographic network extracted from SRTM (red) and Topodata (green).

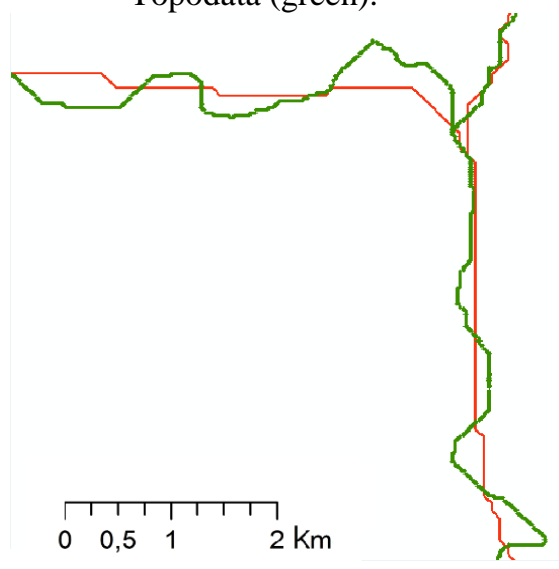

\section{DISCUSSION}

These experiments show that the quality of a DEM can be studied with no ground control. This approach is only a contribution to DEM quality assessment, which does not mean that accuracy assessment is not relevant. However, accuracy assessment is based on the comparison with ground control data which are not always available, and it does not guarantee that the DEM is respectful of terrain shapes. This means that the two approaches are complementary to each other.

Although these experiments show that DEM quality assessment with no ground control is feasible, some limitations can be identified for this approach.

An important limitation is the acceptance of the rules that are used as criteria to evaluate the quality of a DEM in terms of geomorphologic realism. Indeed, the discrepancy between the data and the rule indicates that the relief described by the DEM is improbable but not impossible, so that it is not obvious to guarantee that the mapping technique is responsible for unlikely shapes. However, such a discrepancy may have a spatial behaviour which is coherent, in terms of direction and scale, with the characteristics of the terrain modelling method. In this case, it is highly probable that this discrepancy reveals an artefact rather than a geomorphologic phenomenon (POLIDORI et al. 1991).

Another limitation refers to scale. Our method based on geomorphologic rules, that was applied to the Topodata DEM with a $30 \mathrm{~m}$ mesh, would probably be less relevant for a significantly smaller mesh size, and $30 \mathrm{~m}$ is probably a reasonable threshold under which both the interpolator used to generate the Topodata DEM and the criteria used for shape-based quality assessment would not be relevant. Indeed, high resolution DEMs obtained by aerial photogrammetry show that smaller shapes are likely to contain important contributions from trees, buildings and other manmade structures that are not modelled by geomorphological rules. 
Finally, the main advantage of Topodata is not to provide a higher resolution or smaller mesh size (this could be obtained by a more simple interpolator), but to extend at a more local scale the geomorphological properties that SRTM only describes for shapes larger than $90 \mathrm{~m}$. Moreover, since the oversampling of SRTM from $90 \mathrm{~m}$ to $30 \mathrm{~m}$ is based on geomorphologic assumptions, the influence of the canopy texture that would affect a $30 \mathrm{~m}$ DEM as generated from ASTER data for instance, does not affect the Topodata DEM. Accordingly, this was observed on ASTER-derived drainage, where numerous artefacts were produced in the uplands, while Topodata added meaningful unitary or low-order captions in the same regions to the gross drainage derived from SRTM (FERNÁNDEZ, 2011).

In order to confirm and extend these results, future work will apply the method to a wider variety of landscapes. Experiments will also be carried out to detect potential geomorphologic thresholds around $30 \mathrm{~m}$. Some of the improvements credited to Topodata may be direct consequences of general refinement processes, regardless of interpolations methods. Thus, similar tests with other SRTM-refined DEMs, gridded through different methods (else than Topodata) may be useful to evaluate interpolation methods.

\section{CONCLUSION}

This study has provided a better knowledge of the quality of the Topodata DEM available over Brazil based on an evaluation of the compliance of several geomorphological rules. These rules are based on physical or statistical properties of the terrestrial relief. They have been discussed and tested on a study area of the North-Eastern region of Brazil. The results show that the variability introduced in the data by the kriging algorithm contributes to a better realism of the shapes in Topodata. Future work will consist in testing this approach on different landscapes and different interpolation parameters in order to better understand the effect of elevation resampling of the geomorphological realism of DEMs.

\section{REFERENCES}

BHANG, K. J.; SCHWARTZ, F. W.; \& BRAUN, A. Verification of the vertical error in C-Band SRTM DEM using ICESat and Landsat-7, Otter Tail County, MN. IEEE Transactions on Geoscience and Remote Sensing, 45(1), p. 36-44, 2007.

EHSANI, A. H.; QUIEL, F.; MALEKIAN, A. Effect of SRTM resolution on morphometric feature identification using neural networkdself organizing map. Geoinformatica, 14, p. 405-424, 2010.

EL HAGE, M.; SIMONETTO, E.; FAOUR, G.; POLIDORI, L. Impact of DEM reconstruction parameters on topographic indices. The International Archives of the Photogrammetry, Remote Sensing and Spatial Information Sciences, Paris, France, vol. XXXVIII, part 3B, p. 40-44, 2010. 
EL HAGE, M. Etude de la qualité géomorphologique de modèles numériques de terrain issus de l'imagerie spatiale. PhD dissertation, Conservatoire National des Arts et Métiers, France, 2012.

FARR, T.; KOBRICK, M. The Shuttle Radar Topography Mission, Eos Trans. American Geophys. Union, 82, p. 47, 2001.

FERNÁNDEZ, D. C. J. Avaliação de algoritmos e modelos digitais de elevação para extração da drenagem (Evaluation of algorithms and digital elevation models for drainage extraction). MSc Dissertation. Instituto Nacional de Pesquisas Espaciais (INPE), Brazil, 2011.

JARVIS, A.; RUBIANO, J.; NELSON, A.; FARROW, A.; MULLIGAN, M. Practical Use of SRTM Data in the Tropics: Comparisons with Digital Elevation Models Generated from Cartographic Data. Working Document vol. 198, International Centre for Tropical Agriculture (CIAT), Cali, Colombia, 2004.

KEERATIKASIKORN, C.; TRISIRISATAYAWONG, I. Reconstruction of 30m dem from 90 m SRTM DEM with bicubic polynomial interpolation method. The International Archives of the Photogrammetry, Remote sensing and spatial information Sciences, Vol. XXXVII, Part B1, p.791-794, 2008.

KELLNDORFER, J. M.; WALKER, W. S.; PIERCE, L. E.; DOBSON, M. C.; FITES, J.; HUNSAKER, C. Vegetation height derivation from shuttle radar topography mission and national elevation data sets. Remote Sensing of Environment, 93, p.339-358, 2004.

LE TOAN, T.; BEAUDOIN, A.; RIOM, J.; GUYON, D. Relating forest biomass to SAR data. IEEE Transactions on Geoscience and Remote Sensing, 30, p.403411, 1992.

LI, Z. Variation of the accuracy of digital terrain models with sampling interval. Photogrammetric Record, 14 (79), p.113-128, 1992.

METZ, M.; MITASOVA, H.; HARMON, R. S. Accurate stream extraction from large, radar-based elevation models. Hydrology Earth Systems Science Discussions, 7, p.3213-3235, 2010.

MICELI, B. S.; DIAS, F. M.; SEABRA, F. M.; SANTOS, P. R. A.; FERNANDES, M. C. Avaliação vertical de modelos digitais de elevação (MDEs) em diferentes configurações topográficas para médias e pequenas escalas. Revista Brasileira de Cartografia, 63(1), p.191-201, 2011.

MILIARESIS, G. C.; PARASCHOU, C. V. E. Vertical accuracy of the SRTM DTED level 1 of Crete. International Journal of Applied Earth Observation and Geoinformation, 7(1), p.49-59, 2005.

OKSANEN, J. Tracing the Gross Errors of DEM - Visualisation Techniques for Preliminary Quality Analysis, Proc. of the 21st International Cartographic Conference, August 10-16, 2003, Durban, South Africa, CD-ROM, pp. 24102415, 2003. 
POLIDORI, L. Réflexions sur la qualité des modèles numériques de terrain. Bulletin de la Societé Française de Photogrammétrie et de Télédétection, vol. 139, p. 10-19, 1995.

POLIDORI, L.; CHOROWICZ, J; GUILLANDE, R. Description of terrain as a fractal surface, and application to digital elevation model quality assessment, Photogrammetric Engineering and Remote Sensing, 57 (10), p. 1329-1332, 1991.

RABUS, B.; EINEDER, M.; ROTH, A.; BAMLER, R. The shuttle radar topography mission - a new class of digital elevation models acquired by spaceborne radar. ISPRS Journal of Photogrammetry and Remote Sensing, 57 (4), 241$262,2003$.

RODRIGUEZ-ITURBE , I.; RINALDO, A. Fractal river basins: chance and selforganization. Cambridge University Press, 564 p., 1997.

RODRIGUEZ, E.; MORRIS, C. S.; BELZ, J. E. A global assessment of the SRTM performance. Photogrammetric Engineering and Remote Sensing, 72 (3), p. 249-260, 2006.

SAADI, A. A geomorfologia da Serra do Espinhaço em Minas Gerais e de suas margens, Geonomos, 3 (1), p. 41-63, 2013.

SMITH, B.; SANDWEL, D. Accuracy and resolution of shuttle radar topography mission data, Geophys. Res. Letters, vol. 30, N9, 1467, doi:10.1029/2002 GL016643, 2003.

TOUTIN, T.; GRAY, A. L. State-of-the-art of extraction of elevation data using satllite SAR data. ISPRS Journal of Photogrammetry and Remote Sensing, 5 (1), p. 13-33, 2000.

VALERIANO, M. M.; ROSSETTI, D. F. Topodata: Brazilian full coverage refinement of SRTM data. Applied Geography (Sevenoaks, England), 32, p. 300-309, 2012.

VALERIANO, M. M.; KUPLICH, T. M.; STORINO, M.; AMARAL, B. D.; MENDES, J. N. JR.; LIMA, D. Modeling small watersheds in Brazilian Amazônia with SRTM-90 m data. Computers and Geosciences, 32, p. 11691181, 2006.

WEYDAHL, D. J.; SAGSTUEN, J.; DICK, Ø. B.; RØNNING, H. SRTM DEM accuracy assessment over vegetated areas in Norway. International Journal of Remote Sensing, 28(16), p. 3513-3527, 2007.

WISE, S. Cross-validation as a means of investigating DEM interpolation error. Computers and Geosciences, 37 (8), p. 978-991, 2011.

(Recebido em outubro de 2013. Aceito em março de 2014). 